\title{
Turismo alternativo como estrategia de desarrollo local en el municipio de Chalan - Sucre ${ }^{1}$
}

\section{Alternative tourism as a local development strategy in the municipality of Chalán - Sucre}

\author{
DOI: http://dx.doi.org/10.17981/econcuc.39.1.2018.08
}

Artículo de investigación. Fecha de recepción: 19/12/2017 Fecha de aceptación: 25/05/2018

\author{
Angélica María Aguirre Bertel \\ Corporación Universitaria del Caribe-CECAR (Colombia) \\ angelicaaguirre@hotmail.com \\ Lisset Paola Arroyo Oviedo (D) \\ Universidad de Sucre (Colombia) \\ lissetempresaria@gmail.com \\ Clarisa Isabel Navarro Mesa (D) \\ Universidad de Sucre (Colombia) \\ claribell_31@hotmail.com
}

Para citar este artículo:

Aguirre, A., Arroyo, L. y Navarro, C. (2018). Turismo alternativo como estrategia de desarrollo local en el municipio de Chalan - Sucre. Económicas CUC, 39(1). 117-136. DOI: http://dx.doi.org/10.17981/econcuc.39.1.2018.08

\section{Resumen}

Este artículo propone la aplicación de una metodología para la elaboración de estrategias de desarrollo local en comunidades poco favorecidas en el contexto actual de la globalización, pero con las condiciones propicias para coadyuvar el desarrollo desde el aprovechamiento de sus recursos endógenos. Tomando como referente metodológico los lineamientos estratégicos que se desarrollan en pro de alcanzar los objetivos propuestos desde la identificación de la vocación. Así mismo, se presentan los resultados de cada fase de la metodología aplicados al municipio de Chalán en el Departamento de Sucre, donde se plantea el turismo alternativo como una estrategia de desarrollo local a través del diseño de un producto turístico que conduciría a mejorar las condiciones socioeconómicas de esta comunidad.

Palabras claves: Turismo alternativo, desarrollo local, planeación estratégica.

\section{Abstract}

This article proposes the application of a methodology for the elaboration of local development strategies in underprivileged communities in the current context of globalization, but with the favorable conditions to contribute to the development from the use of their endogenous resources. Taking as a methodological reference the strategic guidelines that are developed in order to reach the proposed objectives from the identification of the vocation. Likewise, the results of each phase of the methodology applied to the municipality of Chalán in the Department of Sucre are presented, where alternative tourism is proposed as a local development strategy through the design of a tourism product that would lead to improving the socio-economic conditions of this community.

Keywords: Alternative tourism, local development, strategic planning.

\footnotetext{
${ }^{1}$ Este artículo es producto de la tesis "Chalán, municipio destino turístico en el Departamento de Sucre: Diseño de un producto turístico", presentada por Lisset Arroyo como requisito para obtener el título de Magíster en Administración de la Universidad Tecnológica de Bolívar (Colombia).
} 


\section{INTRODUCCIÓN}

Los recursos endógenos de una región o localidad representan el punto de partida para la aplicación de un modelo de desarrollo local que conlleve al mejoramiento de la calidad de vida de sus habitantes mediante un sistema socioeconómico que involucra la participación activa de la comunidad y de actores públicos y privados a través del uso eficiente y responsable de los mismos.

La planificación de un nuevo modelo de desarrollo local trasciende al diseño de estrategias acordes a las potencialidades y necesidades de cada comunidad. En este sentido, el turismo aparece como una oportunidad estratégica que privilegia a las regiones que poseen un caudal de recursos naturales y culturales atractivos para la actividad turística.

Por ende, el turismo es considerado uno de los grandes dinamizadores del desarrollo económico de una región, debido a que permite no solo aumentar el flujo de personas, el ingreso de divisas y la creación de empleo, sino también, mejorar la infraestructura de aeropuertos, carreteras, puentes, comunicación electrónica y redes necesarias para el desarrollo del destino turístico y de la sociedad en general, permitiendo de esta manera una mayor interconexión y desarrollo entre los sectores económicos.

Sin embargo, la fuerte dinámica del sector turístico debido a las exigencias del mercado y del entorno, sumergen a las empresas y a las regiones en una realidad impulsada por la globalización, la innovación y la diversificación de productos y servicios. Adaptarse y responder inteligentemente ante los cambios es un reto que se debe afrontar con estrategias de crecimiento y estructurando modelos de organización flexibles y alternativos.

Teniendo en cuenta lo anterior, se requieren esfuerzos desde distintos enfoques que permitan dirigirse a un turista que busca una opción diferente a los paquetes turísticos genéricos, en donde sea posible encontrar una oferta de servicios distinta (naturaleza, religión, patrimonio) con altos estándares de calidad y disfrutar de los secretos del territorio que se visita. Asimismo, brindar garantía en cuanto a la calidad y la diferenciación; por lo que se debe velar en la construcción de las experiencias y articulación de los atractivos. El turismo alternativo emerge como la estratégica para lograr el desarrollo local del municipio de Chalán en el Departamento de Sucre, a través del diseño de un producto turístico que conducira a mejorar la realidad socioeconómica y sociocultural, y potencializar la ventaja comparativa del destino, de la mano de la sustentabilidad, en busca de dar respuesta a las demandas de los territorios.

De este modo, con el objetivo de aplicar una metodología para la elaboración de estrategias de desarrollo local en el sector turismo, se propone un plan estratégico, en el cual se articulan las etapas del proceso de planificación con los resultados de una investigación sobre el diseño de producto turístico.

Turismo alternativo y desarrollo local: aspectos teóricos

\section{- Turismo Alternativo}

El turismo en sus diversas manifestaciones es una actividad que goza de gran aceptación a nivel mundial, al brindar una variedad de opciones tendientes a satisfacer las necesidades de aquellas personas que se trasladan por ocio, salud, educación o negocios, entre otros motivos, a lugares diferentes a los de su entorno habitual.

En este sentido, el turismo se caracteriza por ser un fenómeno social que genera múltiples interrelaciones de carácter social, económico y cultural entre los visitantes y los habitantes de la ciudad receptora. Igualmente, se ha convertido en un eslabón clave para el desarrollo de 
la economía a partir de la generación de empleo, el ingreso de divisas, mejoras en infraestructura y la atracción de la inversión extranjera; lo que le permite a las comunidades avanzar en el desarrollo local sin perder su identidad.

Sin embargo, a partir de los años 80 el contexto turístico empieza a experimentar cambios en las motivaciones de los turistas y se produce un despertar por la ecología y la cultura. Es así como surge el turismo alternativo que según Acerenza (2006):

No es una forma de turismo, sino el nombre genérico con el cual el movimiento por un turismo consciente y responsable denominó a todas aquellas opciones de turismo, distintas a la del turismo masivo, que se caracterizan por permitir un desarrollo en menor escala, con un mínimo impacto sobre el medio ambiente, y respetuoso de los valores de las comunidades locales y su cultura (p. 38).

En el mismo sentido, respondiendo a los cambios en la evolución del turismo moderno, Osorio (2010) asume el turismo alternativo como un modelo de actividad turística, caracterizado como posfordista o posindustrial, que busca promover estructuras de viaje más flexibles y heterogéneas en distintos espacios naturales (áreas naturales protegidas y no protegidas) y artificiales (urbanos y rurales), particularmente en los países sub-desarrollados, donde se reconoce e incorpora a la población local como un actor social necesario.

Por su parte, Ivanoba e Ibañez (2012) consideran que:

El turismo alternativo, es una corriente que tiene como objetivo la realización de viajes donde el turista participa en actividades recreativas de contacto con la naturaleza y las expresiones rurales, indígenas y urbanas, respetando los patrimonios natural, cultural e histórico del lugar que visitan. Presupone que los organizadores están conscientes de los valores naturales, sociales y comunitarios, y que los turistas desean interactuar con la población local (p. 18).
Desde otra perspectiva, según Bringas y Ojeda (2000), el turismo alternativo a diferencia del turismo de masas, le da valor a los atractivos naturales y culturales que existen el mundo y permite diversificar la oferta, orientándola a ambientes naturales diferentes a los de sol y playa que estimulan el desarrollo personal de los turistas.

Por lo anterior, el turismo alternativo responde a las necesidades y expectativas de los turistas que buscan vivir nuevas experiencias, al reencontrarse con la naturaleza e interactuar con la cultura propia de la comunidad receptora. Pero este no solo busca la sustentabilidad del medio ambiente, sino un impacto positivo en el ámbito económico que conlleve a la existencia de ingresos suficientes para todos y que a su vez sea equitativa, así como el desarrollo y bienestar de la comunidad local en general.

Por otra parte, la Secretaría de Turismo mexicana (SECTUR) (2004) "segmentó el turismo alternativo en tres grandes segmentos, cada uno compuesto por diversas actividades como son: el ecoturismo, turismo de aventura y turismo rural” (p. 21)

En este sentido, Ivanoba e Ibañez (2012) argumentan que el Ecoturismo es:

Un nuevo movimiento conservacionista, basado en la industria turística. [...] Promueve la educación y el esparcimiento mediante la observación y estudio de los valores del lugar. Su desarrollo debe generar recursos para la preservación de la cultura y la naturaleza, y para la prosperidad de la comunidad donde se realiza” (p. 22).

En cuanto al turismo aventura, la SECTUR citada en Díaz (2012) lo define como:

La realización de actividades deportivas con fines recreativos, cuyo rasgo distintivo es la superación de diversos desafíos impuestos por la naturaleza. Este tipo de turismo empieza a desarrollarse como consecuencia de un acercamiento por parte de un mercado turístico que demanda la realización de actividades con cierto nivel de riesgo en entornos naturales (p. 532). 
Finalmente, de acuerdo a lo expuesto por Pérez (2010) el turismo rural "toma todos los recursos rurales, los combina y organiza de manera muy diversa en productos turísticos que pueden ofrecer actividades variadas y definen las posibilidades que presentan los territorios rurales en el desarrollo de esta nueva actividad productiva" (p. 510).

Por consiguiente, el turismo alternativo es capaz de jalonar diferentes formas de turismo, generando nuevos productos turísticos opuestos al turismo convencional. Este tipo de turismo integra la población local y se convierte en una actividad que propicia el desarrollo socio-económico local al requerir un mínimo de inversión y la ventaja de contar con un mercado en crecimiento. Pero no solo se requiere de la participación de la comunidad local, el sector público debe hacer presencia mediante la implementación de políticas públicas que conlleven a promover la planificación turística, la inversión en infraestructura y servicios y demás actividades tendientes a mejorar la calidad de vida de la comunidad.

\section{Desarrollo Local}

Gracias a procesos productivos flexivos, avances en las comunicaciones y la informática, la economía mundial ha reconocido la importancia de contar y aprovechar los recursos locales endógenos representados en potencialidades económicas, sociales, culturales, naturales y políticas necesarios para el desarrollo de sistemas socioeconómicos innovadores y competitivos.

A partir de los años ochenta, se piensa en un nuevo escenario para el desarrollo económico, que deja de lado los modelos de crecimiento basados en el capitalismo, por un nuevo modelo que se caracteriza por la descentralización de las actividades económicas. De esta forma surgen nuevos enfoques basados en el desarrollo industrial endógeno en localidades, como son la teoría de los Distritos Industriales (Becattini, 2002), el Modelo de Industrialización
Descentralizada (FUA, 1988), entre otros. Es así, como se empieza a hablar de desarrollo local endógeno, como estrategia de desarrollo en localidades europeas, con la activa intervención del gobierno local en el desarrollo económico (Sanchis, 1999).

En este sentido, Vázquez (2009) sostiene que:

El desarrollo local es una estrategia que, además, busca el progreso social y el desarrollo sostenible. Entiende que el desarrollo es un proceso en el que el crecimiento económico y la distribución de la renta son dos caras de un mismo fenómeno, ya que los actores públicos y privados, cuando deciden y ejecutan sus inversiones, lo hacen con la finalidad de aumentar la productividad y mejorar el bienestar de la sociedad. El desarrollo local es, también, una estrategia que se basa en la mejora continua de los recursos disponibles y particularmente de los recursos naturales y del patrimonio histórico y cultural, ya que con ello se contribuye a aumentar la ventaja competitiva del territorio y el bienestar de la población (pp. 9-10).

Por otra parte, la Asociación Española para el Desarrollo Económico citado en Rubert y Fuertes (2003), define el desarrollo local como: "la optimización del aprovechamiento de los recursos endógenos" (p. 100).

Para Solari y Pérez (2005) el desarrollo local es:

El conjunto de resultantes que se manifiestan en el mejoramiento del nivel y calidad de vida de los habitantes de una localidad a raíz de generar crecimientos sustentables a diversos niveles, que se engranan, concatenan, implican y complementan entre sí de manera estratégica, capaces de crear sinergias locales de mejoramiento que implican el cambio de las condiciones sistémicas y estructurales de la localidad, profundizándose a largo plazo en la medida en que se forma y fortalece un núcleo endógeno básico (p. 52).

Mientras que Arocena citado en Vázquez (2007), define el desarrollo local como, 
un proceso que combina la sostenibilidad económica con la social, ya que los actores públicos y privados toman las decisiones de inversión no solo con la finalidad de mejorar la productividad y la competitividad de las empresas, sino también con el fin de resolver los problemas y mejorar el bienestar de la sociedad" (p. 204).

Por ende, la teoría de desarrollo local crea una visión territorial que conduce a la integración y aumento de la producción en un territorio determinado, en donde las fuerzas del desarrollo económico se compactan teniendo como protagonistas a la comunidad local. Igualmente, es necesario destacar que pueden darse diferentes formas de crecimiento a partir de los recursos disponibles (recursos medioambientales, mano de obra, capacidad empresarial e instituciones de apoyo públicas y privadas). Pero es precisamente, la endogeneidad lo que les permite a las comunidades reinventarse a partir de sus recursos y potencializar su tejido productivo.
Así mismo, Silva (2003) establece ciertas características de los procesos de desarrollo local que deben tenerse en cuenta al momento de plantear una estrategia de desarrollo local, como se describen en la tabla 1. En este sentido, el desarrollo local parte de establecer el potencial de recursos que puede tener una localidad y que pueden estar siendo subutilizados sin beneficio alguno para la comunidad en general. Para explotar y potencializar adecuadamente los recursos que permitirían un desarrollo local sostenible, Silva (2003) propone una Metodología que conlleva a la planificación estratégica del desarrollo local mediante una serie de actividades metodológicas que se interrelacionan entre sí y que conllevan al fomento productivo, creación de empleo, formación de recursos humanos e infraestructuras de apoyo, tal como se muestra en la Fig. 1. De igual manera, de acuerdo a lo planteado por Silva (2003) se describen cada una de las fases en la Tabla 2.

TABLA 1

Características de los Procesos de Desarrollo Local.

\begin{tabular}{ll}
\hline \multicolumn{1}{c}{ Características } & \multicolumn{1}{c}{ Descripción } \\
\hline $\begin{array}{l}\text { Naturaleza } \\
\text { Endógena }\end{array}$ & $\begin{array}{l}\text { Son procesos que se impulsan conscientemente, revalorizan el conjunto de } \\
\text { recursos locales y buscan la utilización óptima de su potencial. }\end{array}$ \\
$\begin{array}{l}\text { Solidaridad con el } \\
\text { Territorio }\end{array}$ & $\begin{array}{l}\text { El desarrollo local es generado a partir del trabajo y el esfuerzo social y } \\
\text { económico de la comunidad. Entendiendo lo local como un espacio geográfico } \\
\text { con características propias. }\end{array}$ \\
$\begin{array}{l}\text { Voluntad de } \\
\text { Gestión Asociativa }\end{array}$ & $\begin{array}{l}\text { No es posible desarrollarse aisladamente, por lo que se requiere consensuar } \\
\text { un objetivo común que sumen esfuerzos en el corto, mediano y largo plazo. }\end{array}$ \\
Liderazgo & $\begin{array}{l}\text { Se requiere la disposición de ejercer el liderazgo en los procesos locales por } \\
\text { parte de los diferentes agentes (empresarios, universidades, actores públicos }\end{array}$ \\
y privados y comunidad local), con el fin de alcanzar los objetivos estratégicos.
\end{tabular}

Fuente: elaboración propia a partir de lo expuesto por Silva, 2003. 


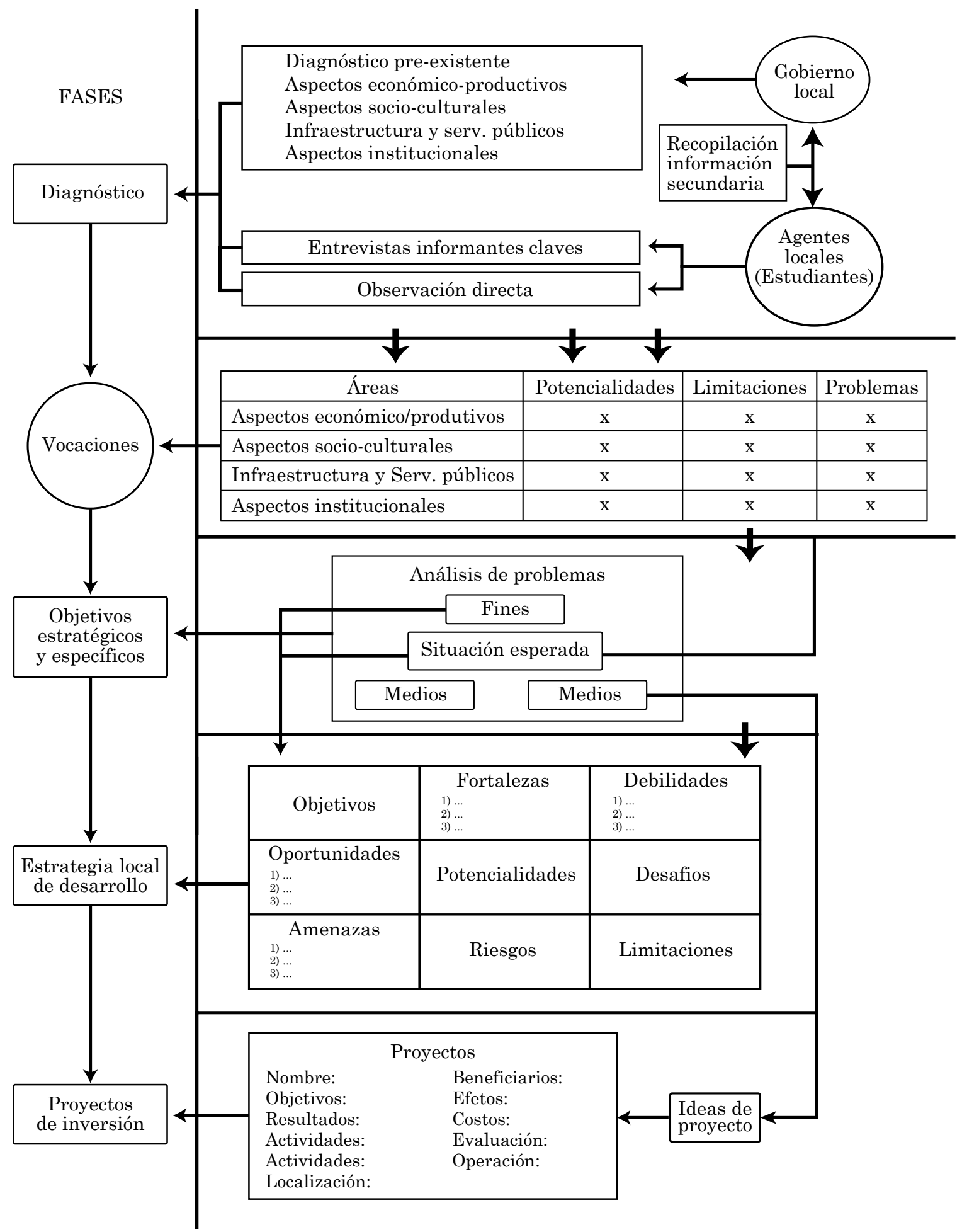

Fig. 1. Fases de la Planificación Estratégica

Fuente: Silva, 2003. 
TABla 2

Fases de la Planificación Estratégica

\begin{tabular}{|c|c|}
\hline Fases & Descripción \\
\hline Diagnóstico & $\begin{array}{l}\text { El objetivo fundamental de todo el proceso de recogida, tratamiento } \\
\text { y difusión de la información es la elaboración de un diagnóstico que } \\
\text { sirva de base a los agentes locales para el establecimiento y puesta } \\
\text { en marcha de la estrategia de desarrollo (p. } 21 \text { ). }\end{array}$ \\
\hline Vocación & $\begin{array}{l}\text { Se definen a partir de la matriz de potencialidades y limitaciones, } \\
\text { entendidas como la aptitud, capacidad o característica especial que } \\
\text { tiene el territorio para su desarrollo. Como resultado se pueden } \\
\text { definir dos o tres grandes vocaciones, alcanzables a mediano plazo y } \\
\text { en las que se podría concentrar el proceso de desarrollo local (p. 27). }\end{array}$ \\
\hline $\begin{array}{l}\text { Objetivos } \\
\text { Estratégicos } \\
\text { y Específicos }\end{array}$ & $\begin{array}{l}\text { A partir de esta fase se debe promover la definición de la estrategia } \\
\text { de desarrollo que contenga los objetivos a los que se desea llegar } \\
\text { y la determinación de líneas de acción que permitan alcanzar los } \\
\text { objetivos identificados (p.29). }\end{array}$ \\
\hline $\begin{array}{l}\text { Estrategia } \\
\text { local de } \\
\text { desarrollo }\end{array}$ & $\begin{array}{l}\text { Después de definir los objetivos, el siguiente paso es decidir cómo } \\
\text { se quiere llegar a ellos, es decir, líneas de acción y de intervención } \\
\text { necesarias para lograr las metas las metas propuestas (p. 41). }\end{array}$ \\
\hline $\begin{array}{l}\text { Proyectos de } \\
\text { inversión }\end{array}$ & $\begin{array}{l}\text { Para materializar los objetivos de desarrollo, a través de la } \\
\text { estrategia seleccionada, se requiere identificar y seleccionar los } \\
\text { proyectos de inversión que darán concreción efectiva al plan de } \\
\text { desarrollo (p. 20). }\end{array}$ \\
\hline
\end{tabular}

Fuente: basado en lo propuesto por Silva, 2003.

\section{Metodología}

Para el desarrollo del presente artículo, se propone un plan estratégico de desarrollo local, en el cual se articulan las etapas del proceso de planificación con los resultados de la investigación; se inicia por el diagnóstico, luego con la identificación de las vocaciones del territorio; la asignación de objetivos estratégicos; la elaboración de una estrategia local de desarrollo, y las recomendaciones de acciones específicas, en la forma de proyectos y/o políticas que permitan implementarla para alcanzar los objetivos en función de las vocaciones detectadas. Lo anterior conforme a la Metodología para la elaboración de estrategias de desarrollo local propuesta por Silva (2003) tal como lo muestra la Fig. 2.
La estrategia planteada propone un nuevo estilo de desarrollo desde el aprovechamiento de los recursos endógeno del municipio de Chalán en aras de ser trabajada con los agentes de cambio locales encargados de impulsar los procesos de fomento productivo destinados a dinamizar la economía de la región. Estos últimos son los actores públicos y privados lo cuales se resumen básicamente en las autoridades locales, universidades, cámaras empresarias, centros de formación, agencias de desarrollo local, y otros, que es importante que transiten por estos procesos de generación de confianza que potenciarán su accionar (Silva, 2003). 


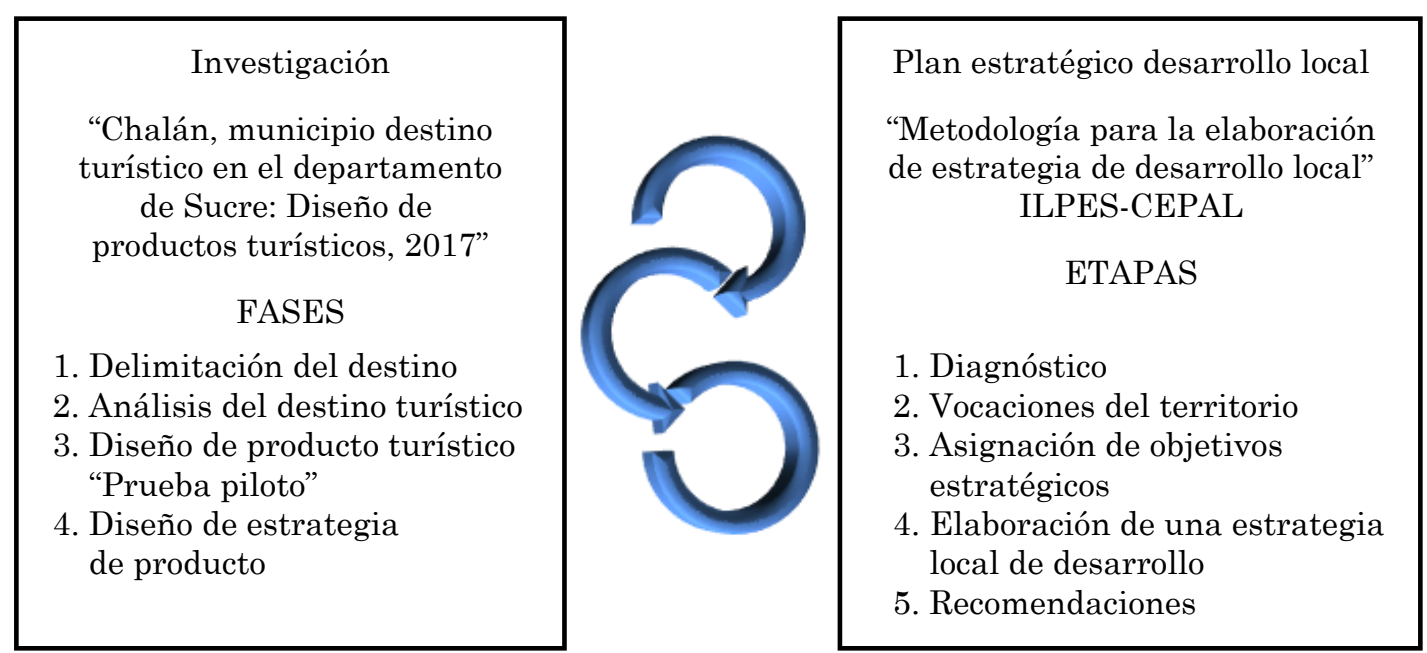

Fig. 2. Articulación de resultados de investigación para el desarrollo de estrategias de desarrollo local.

Fuente: elaboración propia.

\section{Articulación resultados de investigación para el desarrollo de estrategias de desarrollo local: Chalán-Sucre}

\section{- Diagnóstico}

Chalán es un municipio que se encuentra ubicado en la Costa Caribe colombiana, en el nororiente del Departamento de Sucre como parte del sistema montañoso de la serranía de San Jacinto, en los Montes de María. Es el municipio más pequeño del departamento con una extensión de $80 \mathrm{~km}^{2}$. Hace parte de la Subregión Montes de María, en la cual se localiza la reserva forestal protectora conocida como la Serranía de Coraza y Montes de María, entre 200 y 560 m.s.n.m, con 6400 hectáreas de bosques protegido en jurisdicción de los municipios de Toluviejo, Colosó y Chalán. Posee una de las temperaturas más bajas del departamento con un promedio $24^{\circ} \mathrm{C}$. Sus primeros pobladores fueron los indígenas de la etnia Zenú, de donde se desprenden ciertas costumbres y vivencias existentes en la población actual, como son: las viviendas de bahareque, las artesanías, el desarrollo de cultivos, la gastronomía.

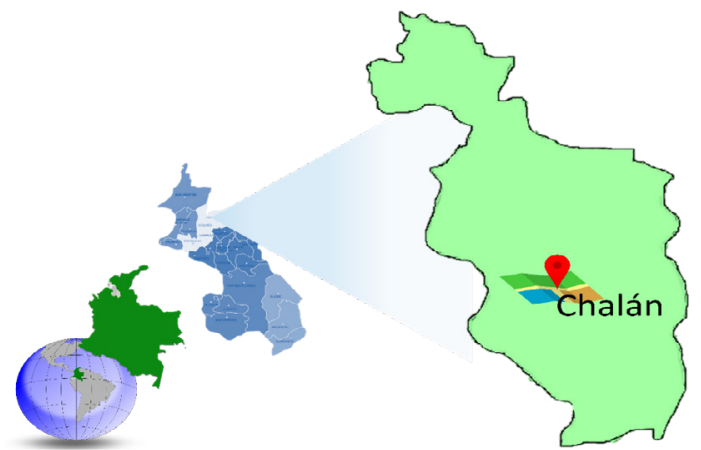

Fig. 3. Chalán-Sucre. Fuente: Arroyo (2017).

En la tabla 3 se detallan las potencialidades, limitaciones y problemas de cada área específica. Entendiéndose por potencialidades los factores humanos, tecnológicos, económicos, financieros, socioculturales, entre otros que se pueden aprovechar para impulsar el desarrollo; mientras que las limitaciones comprenden los factores y situaciones que obstaculizan, dificultan o impiden el desarrollo de las potenciales. Por último, los problemas que se pueden entender como las principales restricciones para el desarrollo del área respectiva. 
TABLA 3

Matriz de identificación de potencialidades, limitaciones y problemas

\begin{tabular}{|c|c|c|c|}
\hline Área Temática & Potencialidades & Limitaciones & Problemas \\
\hline $\begin{array}{l}\text { Sistema Físico - } \\
\text { Natural }\end{array}$ & $\begin{array}{l}\text { Ubicación estratégica } \\
\text { para el desarrollo de } \\
\text { actividades turísticas y } \\
\text { productivas. } \\
\text { Gran potencial de recursos } \\
\text { naturales identificados. } \\
\text { Poseedores de una } \\
\text { Marca Territorial en la } \\
\text { Subregión: 'Montes de } \\
\text { María, cosecha de vida'. }\end{array}$ & $\begin{array}{l}\text { Presencia de grupos al } \\
\text { margen de la ley durante el } \\
\text { conflicto armado. } \\
\text { Escasa planificación } \\
\text { estratégica en el desarrollo } \\
\text { de actividades para el } \\
\text { aprovechamiento de los } \\
\text { recursos. }\end{array}$ & $\begin{array}{l}\text { Mala imagen } \\
\text { de seguridad } \\
\text { del territorio } \\
\text { para desarrollar } \\
\text { actividades } \\
\text { turísticas. } \\
\text { Inadecuada } \\
\text { explotación de } \\
\text { recursos naturales. } \\
\text { Pérdida futura del } \\
\text { patrimonio natural. }\end{array}$ \\
\hline Área Económica & $\begin{array}{l}\text { Posee tierras fértiles para } \\
\text { el desarrollo de diferentes } \\
\text { actividades económicas } \\
\text { (ganadería semintensivas, } \\
\text { agricultura) }\end{array}$ & $\begin{array}{l}\text { Escasas políticas públicas de } \\
\text { desarrollo local. } \\
\text { Precios bajos de la } \\
\text { producción agrícola. } \\
\text { Escasa inversión pública y } \\
\text { privada. } \\
\text { Informalidad en actividades } \\
\text { turística. }\end{array}$ & $\begin{array}{l}\text { Obsolescencia } \\
\text { tecnológica en los } \\
\text { procesos productivos. } \\
\text { Poca demanda de } \\
\text { las actividades } \\
\text { productivas. }\end{array}$ \\
\hline $\begin{array}{l}\text { Demografía } \\
\text { y mercado de } \\
\text { trabajo }\end{array}$ & $\begin{array}{l}\text { Población económicamente } \\
\text { activa entre los } 0 \text { y } 25 \\
\text { años de edad. } \\
\text { Población con amplio } \\
\text { conocimiento en la } \\
\text { elaboración de productos } \\
\text { culturales }\end{array}$ & $\begin{array}{l}\text { Nula gestión del } \\
\text { conocimiento a nuevas } \\
\text { generaciones. } \\
\text { Pocas oportunidades de } \\
\text { empleo formal } \\
\text { Migración de la población } \\
\text { nativa }\end{array}$ & $\begin{array}{l}\text { Pérdida de identidad } \\
\text { cultural. } \\
\text { Bajos niveles de } \\
\text { ingresos en los } \\
\text { hogares. } \\
\text { Mano de obra no } \\
\text { calificada. }\end{array}$ \\
\hline Infraestructura & $\begin{array}{l}\text { Constante presencia } \\
\text { de fuerza pública en el } \\
\text { municipio. } \\
\text { Accesibilidad } \\
\text { Servicios públicos básicos } \\
\text { Viviendas comunitarias } \\
\text { son utilizadas como } \\
\text { hospedaje. } \\
\text { Gran potencial de } \\
\text { recursos culturales }\end{array}$ & $\begin{array}{l}\text { Vías no señalizadas } \\
\text { La calidad del servicio de } \\
\text { agua no es } 100 \% \text { potable. } \\
\text { No existe el servicio formal } \\
\text { de hospedaje } \\
\text { Escasa planificación } \\
\text { estratégica en el desarrollo } \\
\text { de actividades para el } \\
\text { aprovechamiento de los } \\
\text { recursos }\end{array}$ & $\begin{array}{l}\text { Inadecuada } \\
\text { explotación de } \\
\text { recursos culturales. } \\
\text { Nula infraestructura } \\
\text { para el desarrollo } \\
\text { de actividades } \\
\text { turísticas. } \\
\text { Informalidad en } \\
\text { la prestación del } \\
\text { transporte público. }\end{array}$ \\
\hline $\begin{array}{l}\text { Recursos Socio } \\
\text { Culturales }\end{array}$ & $\begin{array}{l}\text { Patrimonio Cultural } \\
\text { material e inmaterial. } \\
\text { Celebraciones culturales }\end{array}$ & $\begin{array}{l}\text { Acontecimientos históricos } \\
\text { de conflicto que azotaron la } \\
\text { comunidad. }\end{array}$ & \\
\hline $\begin{array}{l}\text { Aspectos } \\
\text { Institucionales }\end{array}$ & $\begin{array}{l}\text { Planes de desarrollo } \\
\text { territorial en favor del } \\
\text { desarrollo local. } \\
\text { Conformación de nuevas } \\
\text { Asociaciones. } \\
\text { Firma del acuerdo de Paz. }\end{array}$ & $\begin{array}{l}\text { Desvió de recursos públicos. } \\
\text { No existe priorización para } \\
\text { la ejecución de proyectos que } \\
\text { apunten al desarrollo del } \\
\text { municipio. }\end{array}$ & $\begin{array}{l}\text { No existe } \\
\text { articulación entre } \\
\text { los actores locales y } \\
\text { regionales. }\end{array}$ \\
\hline
\end{tabular}

Fuente: elaboración propia a partir de los resultados de la investigación. 


\section{- Vocación}

El Municipio de Chalán goza de las condiciones propicias para desarrollar dentro sus posibilidades, un turismo vivencial con la naturaleza acorde a las expectativas y necesidades de los turistas actuales, sin olvidar la riqueza cultural heredada de sus ancestros; y una población con muchas historias por contar, pero sobre todo con la ilusión de un renacer para su región a partir de sus recursos naturales y culturales. Por ende, el desarrollo de la actividad turística ejecutada desde una perspectiva integral a partir de sus potenciales puede convertirse en una alternativa de desarrollo local que afirme su identidad cultural y conlleve al crecimiento económico y mitigar las desigualdades sociales existentes en la localidad.

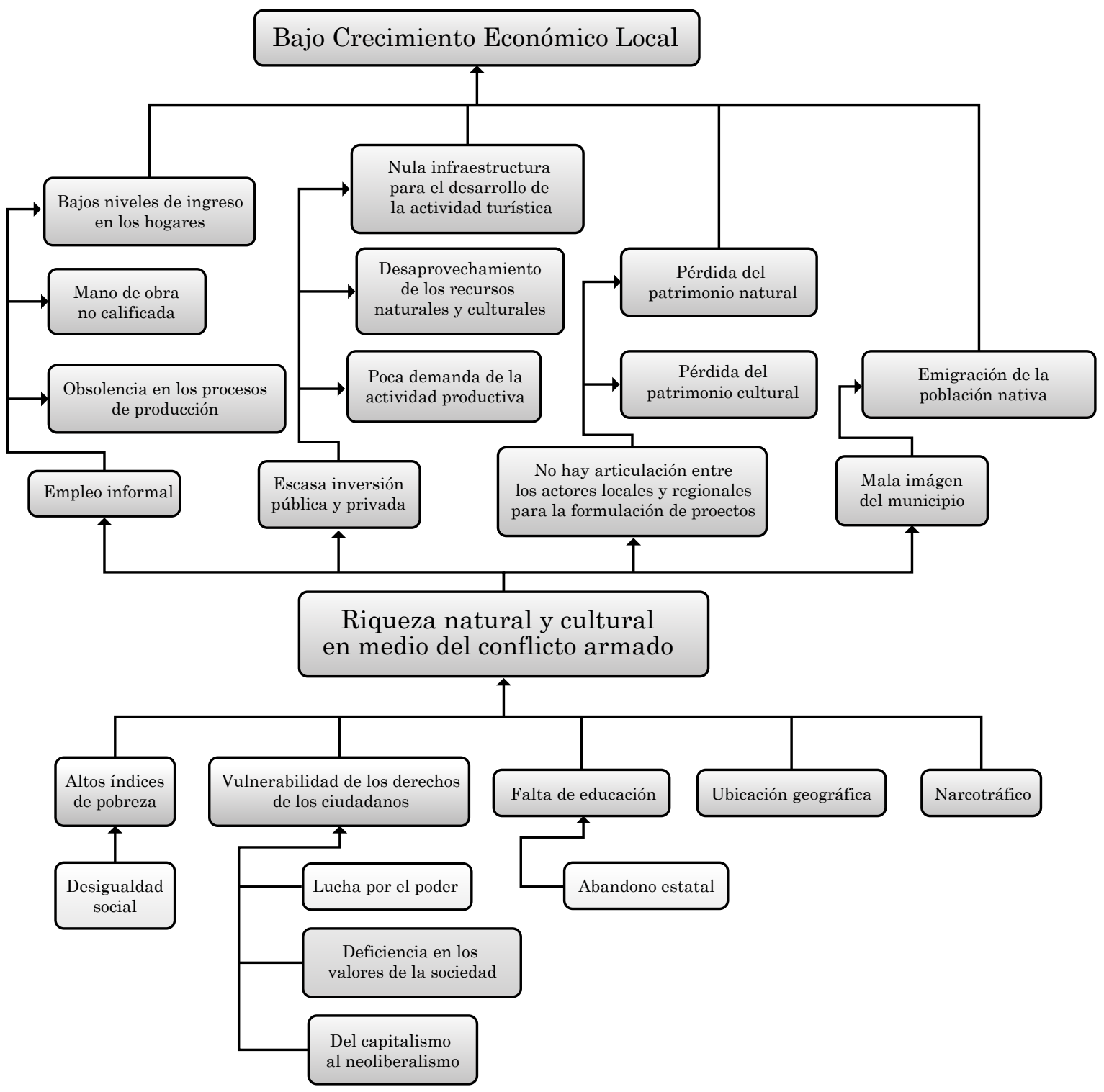

Fig 4. Árbol de Causa y Efecto Fuente: elaboración propia. 


\section{- Objetivos Estratégicos y Específicos}

La identificación y análisis del problema, es el primer paso para la determinación de los objetivos estratégicos de desarrollo, mediante la elaboración del árbol de causas y efectos como lo muestra la Fig. 4.

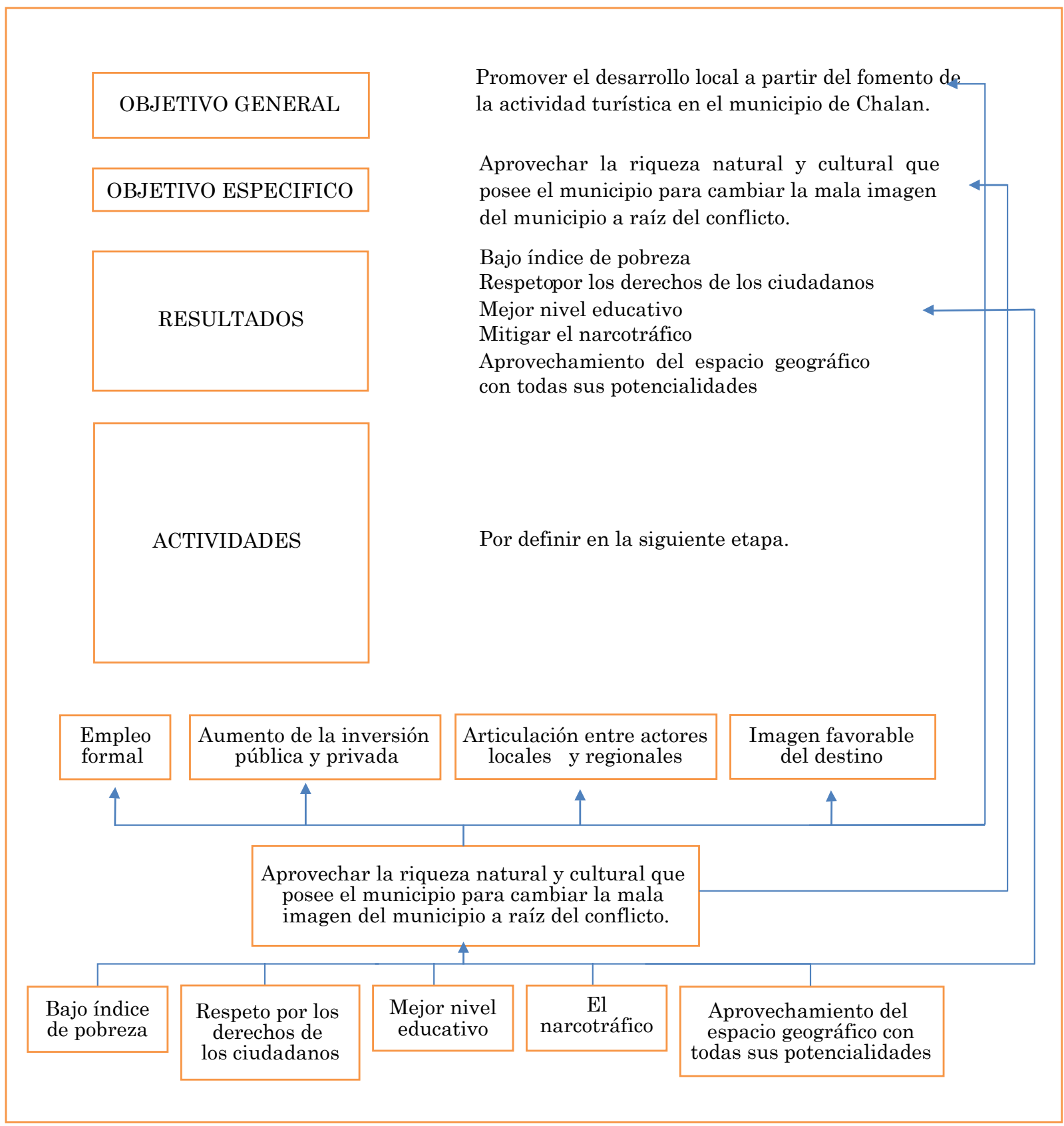

Fig. 5. Asignación de Objetivos

Fuente: elaboración propia. 
Una vez identificado el problema, este se transforma en el gran objetivo de planificación, tal y como lo muestra la Fig. 5.

\section{- Estrategias de Desarrollo Local}

Definidos los objetivos, se procede a describir las estrategias necesarias para lograr las metas propuestas. Para lo anterior, se realiza un análisis de las fortalezas, oportunidad, debilidades y amenazas (FODA) del municipio de Chalán. Las estrategias se formularon de la siguiente forma:

- Aprovechar las oportunidades y las fortalezas;

- Superar las debilidades con las oportunidades;

- Superar las amenazas con las fortalezas,

- Neutralizar las amenazas.

TABLA 4

Matriz de Fortalezas, Oportunidades, Debilidades, Amenazas (FODA)

\begin{tabular}{|c|c|c|}
\hline Objetivos & Fortalezas & Debilidades \\
\hline $\begin{array}{l}\text { Objetivo específico: } \\
\text { Fortalecer los recursos culturales } \\
\text { y naturales a través de la gestión } \\
\text { turística para cambiar la mala } \\
\text { imagen del municipio a raíz del } \\
\text { conflicto armado. }\end{array}$ & $\begin{array}{l}\text { 1. Presencia del municipio en área de } \\
\text { reserva natural (Reserva Coraza) } \\
\text { con diversidad de fauna, flora y } \\
\text { caídas de agua, de la cual hacen } \\
\text { parte también, los municipios } \\
\text { vecinos de Colosó y Tolúviejo. } \\
\text { 2. Proyectos de reforestación } \\
\text { vigentes. } \\
\text { 3. Historias conocidas por los } \\
\text { habitantes. } \\
\text { 4. Existencia de un inventario } \\
\text { turístico cultural y natural del } \\
\text { municipio. } \\
\text { 5. Disposición y participación } \\
\text { activa la comunidad y el ente } \\
\text { gubernamental en eventos } \\
\text { culturales. } \\
\text { 6. Preservación de las actividades } \\
\text { culturales a través de maestros y } \\
\text { escuelas. } \\
\text { 7. Preservación de las actividades } \\
\text { culturales a través de maestros y } \\
\text { escuelas. } \\
\text { 8. Existencia de viviendas de } \\
\text { arquitectura vernácula (1700 - } \\
\text { 1900) con importancia regional y } \\
\text { guardan su estructura original. } \\
\text { 9. Interés de los pobladores y } \\
\text { empresarios de servicios en } \\
\text { formarse en temas afines a } \\
\text { turismo. } \\
\text { 10. Existencia de tradición artesanal } \\
\text { con materiales de la región. }\end{array}$ & $\begin{array}{l}\text { 1. Nula infraestructura de } \\
\text { servicios turísticos en el } \\
\text { municipio. } \\
\text { 2. Zonas de reserva amenazadas } \\
\text { por malas prácticas } \\
\text { ambientales. } \\
\text { 3. Contaminación de aguas. } \\
\text { 4. Ausencia de procesos de } \\
\text { investigación arqueológica. } \\
\text { 5. Uso no estratégico de los } \\
\text { medios de comunicación. } \\
\text { 6. Escasos servicios disponibles. } \\
\text { Débil organización gremial } \\
\text { 7. Falta de interés de los } \\
\text { jóvenes por la conservación de } \\
\text { tradiciones artesanales. } \\
\text { 8. Informalidad en la oferta de } \\
\text { servicios turísticos. } \\
\text { 9eterioro de Viviendas } \\
\text { antiguas de tipo patrimonial } \\
\text { sin declaratoria. } \\
\text { 10. No articulación entre el } \\
\text { potencial cultural y natural. } \\
\text { 11. Difícil acceso a la zona de } \\
\text { reserva. } \\
\text { 12. Desconocimiento en cuanto } \\
\text { al proceso de formulación de } \\
\text { proyectos }\end{array}$ \\
\hline
\end{tabular}


Cont...

\begin{tabular}{ll}
\hline \multicolumn{1}{c}{ Oportunidades } \\
\hline 1. \\
Tendencia aumento de la \\
demanda turismo natural y \\
cultural. \\
2. $\begin{array}{l}\text { Localización Estratégica en } \\
\text { los Montes de María. }\end{array}$ \\
3. Aumento de proyectos \\
enfocados al turismo \\
de naturaleza en zonas \\
prioritarias para proyectos de \\
posconflicto. \\
4. La Zona de reserva como \\
parte de la Red Nacional de \\
Parques Naturales. \\
5. Instituciones en busca de \\
formar personas en carreras \\
afines al sector. \\
6. Apoyo del Ministerio de las \\
TIC's a promover proyectos \\
para la maximización de este \\
servicio en el departamento. \\
Estructura de una cadena \\
productiva del sector \\
elaborada y apropiada por la \\
comisión de Competitividad \\
Departamental, Cámara \\
de comercio, empresarios y \\
comunidad.
\end{tabular}

1. Mala imagen de seguridad del Municipio a nivel departamental y nacional.

2. No aprovechamiento de recursos económicos de orden nacional y departamental.

3. Falta de cohesión entre los diferentes destinos turísticos en el Departamento.

4. No implementación del clúster en el departamento el cual impide ser competitivos.

5. Alto nivel de informalidad en el empleo para el sector.

6. Pérdida de patrimonio (Cultural y Natural)

7. No creación de una dependencia para el sector turístico en el Departamento y en los municipios que poseen este potencial.

8. Infraestructura básica inadecuada o insuficiente.
1. Generar un banco de proyectos enfocado a la conservación del área de reserva y tradiciones culturales (F1, F2, F5, F6, F8, F10, O3, O4)

2. Capacitar a los habitantes de Chalán en temas relacionados con el turismo (Guianza, Hotelería, Bilingüismo) (F4, F5, F9, O1, O5, O7)

3. Promocionar el municipio de Chalán como un destino cultural y natural, a través de otros destinos en el Departamento. (F1, F3, F8, O2, O3, O4, O6, O7)

4. Crear Rutas Turísticas desde el municipio de Sincelejo que muestran las potencialidades que posee el municipio (F2, F5, F6, F7, O1, O3, O4, O7)

1. Crear la imagen turística del municipio, que dado el ambiente de posconflicto, facilitará la promoción del destino (F4, F6, F10, A1, A4).

2. Desde el ente gubernamental, encargar a un comité para la realización de proyectos que permita acceder a los recursos de orden nacional y departamental (F5, F6, F9, A2, A5).

3. A través de cámara de comercio y otras institucionalidades, incentivar a la formalización de la actividad turística y formación (F9, A5, A8).

4. Otorgar las facultades suficientes para que la dependencia de asuntos culturales trabaje en pro de incentivar el turismo cultural en el municipio (F5, F6, F10, O2, O6, 07).

5. Desde las escuelas, impartir cultura ambiental a los niños para la conservación de la reserva ( $\mathrm{F} 1$, F2, F4, F6, A4, A6).
Estrategias Defensivas

1. Creación de canales efectivos de comunicación a través de las TIC's, que permitan promocionar el destino (D5, O1, O6).

2. Crear programas que busquen utilizar las viviendas con características de la región como posadas. (D1, D6, D8, D9, O1, O3).

3. Articulación de las Universidades con acciones como pasantías y proyectos de investigación aplicadas al desarrollo turístico alternativo (D2, D4, D12, O3, O5).

4. Formar a los habitantes dentro del mismo municipio a través de instituciones como el SENA, en programas afines al conocimiento de la cultura y la Naturaleza (D2, D3, D6, D10, O1, O4. O5)

5. Construcción de infraestructura turística, Alojamientos sostenibles, señalización para facilitar el acceso a la zona (D1, D6, D8, D11, O1, O3, O4, O7).

6. Creación de productos turísticos enlazando el patrimonio cultural con el natural (D1, D6, D8, D11, O1, O3, O4, O7)

1. Sensibilizar a la población de Chalán, y así visionen el turismo como una posibilidad de desarrollo sostenible (D2, D3, D6, D7, D10, A2 A5, A6).

2. Desarrollo de ruedas de socialización permanente con las organizaciones donde se expongan las necesidades ante los cambios a nivel departamental (D6, D8, A2).

3. Orientar a los líderes culturales y empresas de servicios en la implementación de los medios de comunicación a través de las TIC's (D5, A1, A3)

4. Recuperación y sistematización de archivos documentales referentes a la historia del municipio y saberes ancestrales (D4, D7, D9, A3, A6). 


\section{- Proyecto de Inversión}

Terminado el análisis FODA acorde a la metodología establecida por Silva (2003), se propone como estrategia de desarrollo local un Proyecto de Inversión enfocado al diseño de un Producto Turístico en el municipio de Chalán, que permitiría integrar la cultura y la naturaleza creando paquetes turísticos donde se incluya la cabecera municipal de Chalan, junto con su parte cultural material e inmaterial, y la Reserva Coraza Montes de María que se encuentra en la jurisdicción del municipio en el cual se incluyen atractivos naturales y culturales.

El diagnóstico del municipio resalta el gran potencial natural y cultural que posee esta magnífica zona de los Montes de María, sin dejar a un lado un pasado que enluta y entristece a la comunidad local. Sin embargo, este paso por el conflicto armado se convierte en un componente histórico para la propuesta del diseño del producto turístico que conlleva no sólo a describir las vivencias de la población, sino a descubrir que pese a sus debilidades existen estrategias y mecanismos que pueden lograr un renacer para la comunidad desde el ámbito social, económico, político y cultural.

En este sentido, EXPLORA CHALÁN se convierte en la propuesta que enmarca las actividades relacionadas al turismo alternativo ofreciendo un turismo experiencial, ecoturismo y aventura, que busca transmitir el acoplamiento entre la naturaleza, la cultura y la historia que envuelve a la comunidad.

TABla 5

Patrimonio Cultural del Municipio de Chalán

\begin{tabular}{lllc}
\hline Categoría & \multicolumn{1}{c}{ Grupo } & \multicolumn{1}{c}{ Componente } & Cantidad \\
\hline & Patrimonio Cultural Material & Arquitectura Habitacional & 4 \\
& Inmueble & Arquitectura Religiosa & 1 \\
& Arquitectura Institucional & 2 \\
Patrimonio & Inmueble; Grupo urbano o rural & Elementos del Espacio publico & 1 \\
Material & Patrimonio Cultural material & Otro & 1 \\
& Inmueble, Grupo arqueológico & & 1 \\
& Patrimonio Cultural & Obras en el Espacio Publico & 1 \\
& Material Mueble & & 10 \\
& Subtotal Patrimonio Material & Gastronomía y Saberes Culinarios & 1 \\
& & Expresiones Musicales y Sonoras & 1 \\
Patrimonio & Cultural & Expresiones dancísticas & 1 \\
Inmaterial & Inmaterial & Técnicas de elaboración de objetos & 1 \\
& & artesanales e instrumentos & 2 \\
Total & Festividades y Eventos & Fiestas & 6 \\
\hline
\end{tabular}

Fuente: Arroyo (2017) 
TABla 6

Patrimonio Natural del municipio de Chalán

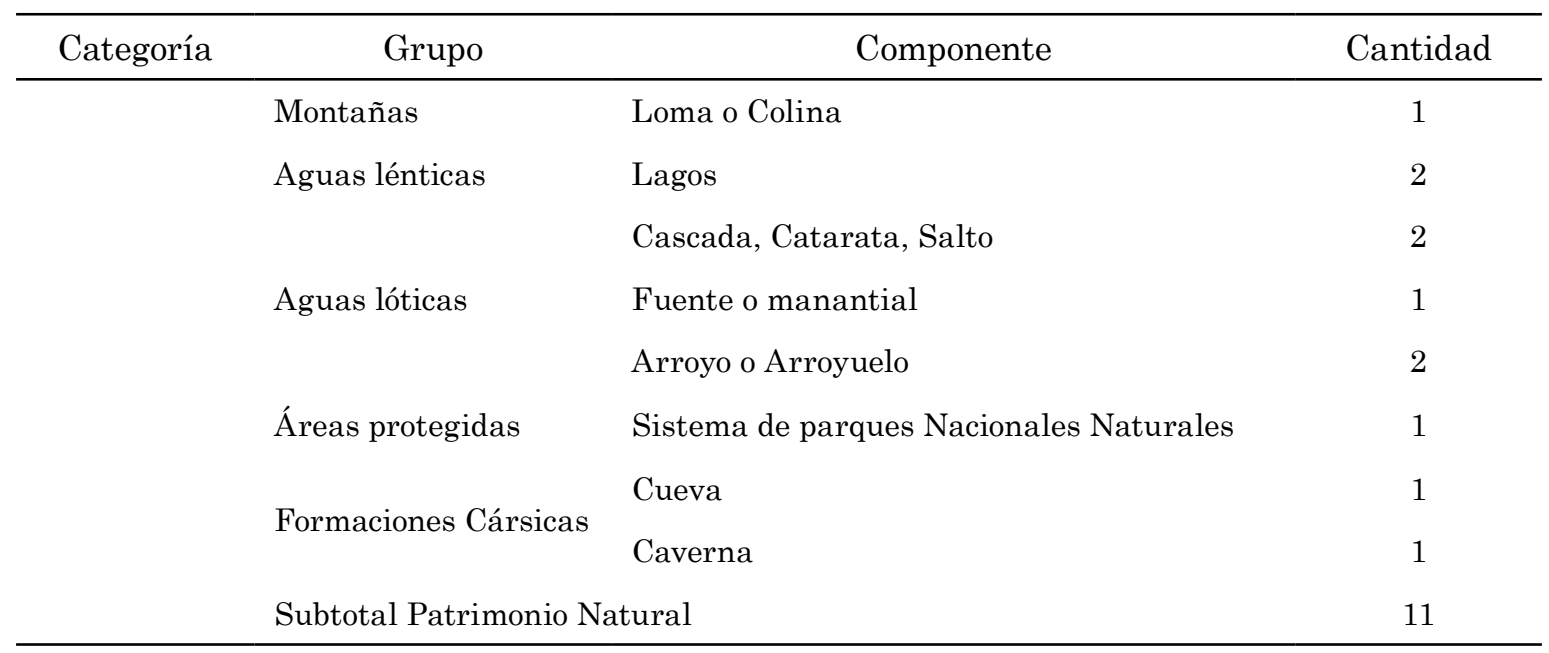

Fuente: Arroyo, 2017.

El producto turístico "EXPLORA $C H A L A N^{\prime \prime}$, plantea el siguiente reto:

Convertir al turismo alternativo en una actividad económica para el municipio de Chalán que permita aprovechar el potencial de los recursos naturales y culturales, mediante la participación activa de la población local en pro de un desarrollo socioeconómico sostenible.

En consecuencia, la oferta turística está integrada por el patrimonio natural y cultural que se presentan en las tablas 5 y 6 .
Por lo anterior, se diseñaron dos formas de disfrutar la oferta turística como son:

- Paquetes de pasadía

- Paquete con alojamiento de 1 noche 2 días.

Con los siguientes itinerarios (Tablas 6 у 7).

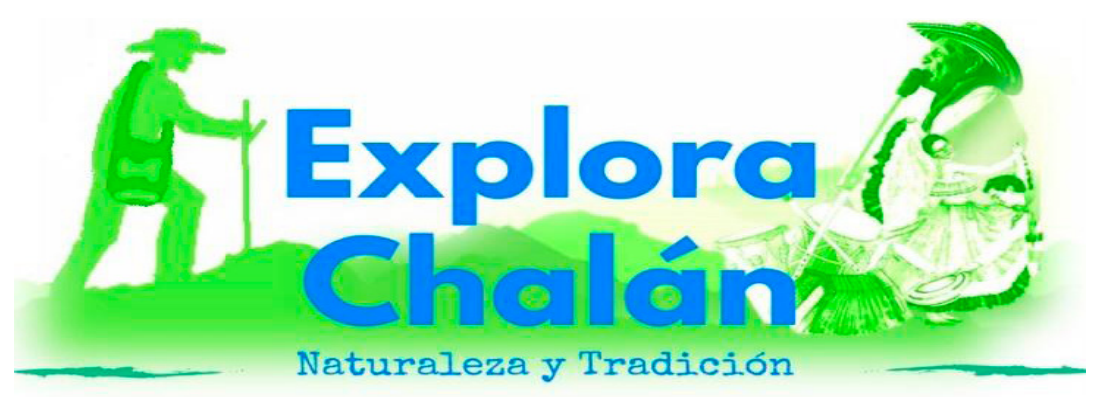

Fig. 6. Explora Chalán.

Fuente: Arroyo, 2017. 
TABLA 7.

Itinerario Paquete Pasadía.

Itinerario paquete Pasadía

\begin{tabular}{|c|c|c|}
\hline Actividad & $\begin{array}{l}\text { Hora de } \\
\text { inicio }\end{array}$ & $\begin{array}{c}\text { Hora de } \\
\text { finalización }\end{array}$ \\
\hline Traslado Sincelejo - Chalán & 8:00 a. m. & 9:30 a. m. \\
\hline \multicolumn{3}{|l|}{ Desayuno en la Palmira } \\
\hline $\begin{array}{l}\text { Recorrido histórico y cultural, } \\
\text { visita a las viviendas antiguas y restos indígenas }\end{array}$ & 10:00 a. m. & 11:00 a. m. \\
\hline Recorrido Sendero las Tinas & 11: 00 a. m. & 01:00 p. m. \\
\hline \multicolumn{3}{|l|}{ Observación de flora y Fauna } \\
\hline Almuerzo & 01:00 p. m. & 02:00 p. m. \\
\hline Descanso & 02:00 p. m. & 03:00 p. m. \\
\hline Muestra artesanal y gastronómica & 03:00 p. m. & 04:00 p. m. \\
\hline Traslado Chalán - Sincelejo & 04:30 p. m. & 06:00 p. m. \\
\hline
\end{tabular}

Servicios Incluidos:

Traslado Sincelejo-Chalán-Sincelejo. Acompañamiento de Guía y Alimentación

Chalán:

Municipio anteriormente atacado por el conflicto. Dado el contexto actual lo primero que se está logrando rescatar después del cese al fuego es su historia, cultura y tradiciones, arraigadas a un pueblo que ahora visiona un Chalán renovado, con olor a maíz, cacao y café y que suene como la gaita, legado del pueblo indígena que aquí reposó hace cientos de años.

Reserva Forestal Serranía Coraza y Montes de María:

La comunidad chalanera piensa en Chalán y observan su serranía, esta es un área de reserva de más de 6 mil hectáreas de bosque seco tropical, con diversidad de flora y fauna. Además de fuentes de agua dulce que recorren lo alto de la serranía.

Fuente: Arroyo, 2017.

En este sentido, EXPLORA CHALÁN se plantea como un medio para alcanzar el desarrollo local del municipio de Chalan. Sin embargo, el producto turístico por sí solo no garantiza el desarrollo local del municipio, se requiere de una serie de actividades que en su conjunto permitirán el logro del objetivo planeado.
EXPLORA CHALÁN, incita al desarrollo del turismo alternativo como estrategia para aprovechar los recursos endógenos que en conjunto con las actividades debidamente planificadas conllevan a una adecuada gestión turística y por ende el impulso del desarrollo local. 
TABla 8.

Itinerario paquete 1 noche 2 dias

\begin{tabular}{|c|c|c|}
\hline \multicolumn{3}{|c|}{ Itinerario Paquete dos días - con alojamiento } \\
\hline Actividad & $\begin{array}{l}\text { Hora de } \\
\text { inicio }\end{array}$ & $\begin{array}{l}\text { Hora de } \\
\text { finalización }\end{array}$ \\
\hline Traslado Sincelejo - Chalán & 8:00 a. m. & 9:30 a. m. \\
\hline Desayuno en La Palmira & 9:30 a. m. & 10:00 a. m. \\
\hline $\begin{array}{l}\text { Recorrido histórico y cultural, } \\
\text { visita a las viviendas antiguas y restos indígenas }\end{array}$ & 10:00 a. m. & 11:00 a. m. \\
\hline $\begin{array}{l}\text { Muestra artesanal y musical } \\
\text { (Ludoteca) }\end{array}$ & 11:00 a. m. & 1:00 p. m. \\
\hline Almuerzo & 1:00 p. m. & 2:00 p. m. \\
\hline Recorrido hacia la cueva del Diablo & 2:30 p. m. & 4:00 p. m. \\
\hline Regreso al casco urbano & 4:00 p. m. & 4:30 p. m. \\
\hline Descanso & 4:30 p. m. & 6:00 p. m. \\
\hline Cena & 6:00 p. m. & 7:00 p. m. \\
\hline Fogata, Música y Danza & 8:00 p. m. & 11:00 p. m. \\
\hline Camping - Hamacas & 11:30 p. m. & 5:00 a. m. \\
\hline Traslado hacia Las Colinas & 5:00 a. m. & \\
\hline Desayuno en las Colinas & 9:00 a. m. & 9:40 a. m. \\
\hline Baño en piscinas naturales - observación de flora y fauna & 10:00 a. m. & 11:59 a. m. \\
\hline Almuerzo & 1:00 p. m. & 2:00 p. m. \\
\hline Traslado hacia el Casco Urbano & & 4:00 p. m. \\
\hline Despedida & 4:00 p. m. & \\
\hline
\end{tabular}

\section{Servicios Incluidos:}

Traslado Sincelejo-Chalán-Sincelejo, Acompañamiento de Guía, Alimentación y Alojamiento

\section{Chalán:}

Municipio anteriormente atacado por el conflicto. Dado el contexto actual lo primero que se está logrando rescatar después del cese al fuego es su historia, cultura y tradiciones, arraigadas a un pueblo que ahora visiona un Chalán renovado, con olor a maíz, cacao y café y que suene como la gaita, legado del pueblo indígena que aquí reposó hace cientos de años.

\section{Reserva Forestal Serranía Coraza y Montes de María:}

La comunidad chalanera piensa en Chalán y observan su serranía, esta es un área de reserva de más de 6 mil hectáreas de bosque seco tropical, con diversidad de flora y fauna. Además de fuentes de agua dulce que recorren lo alto de la serranía. 


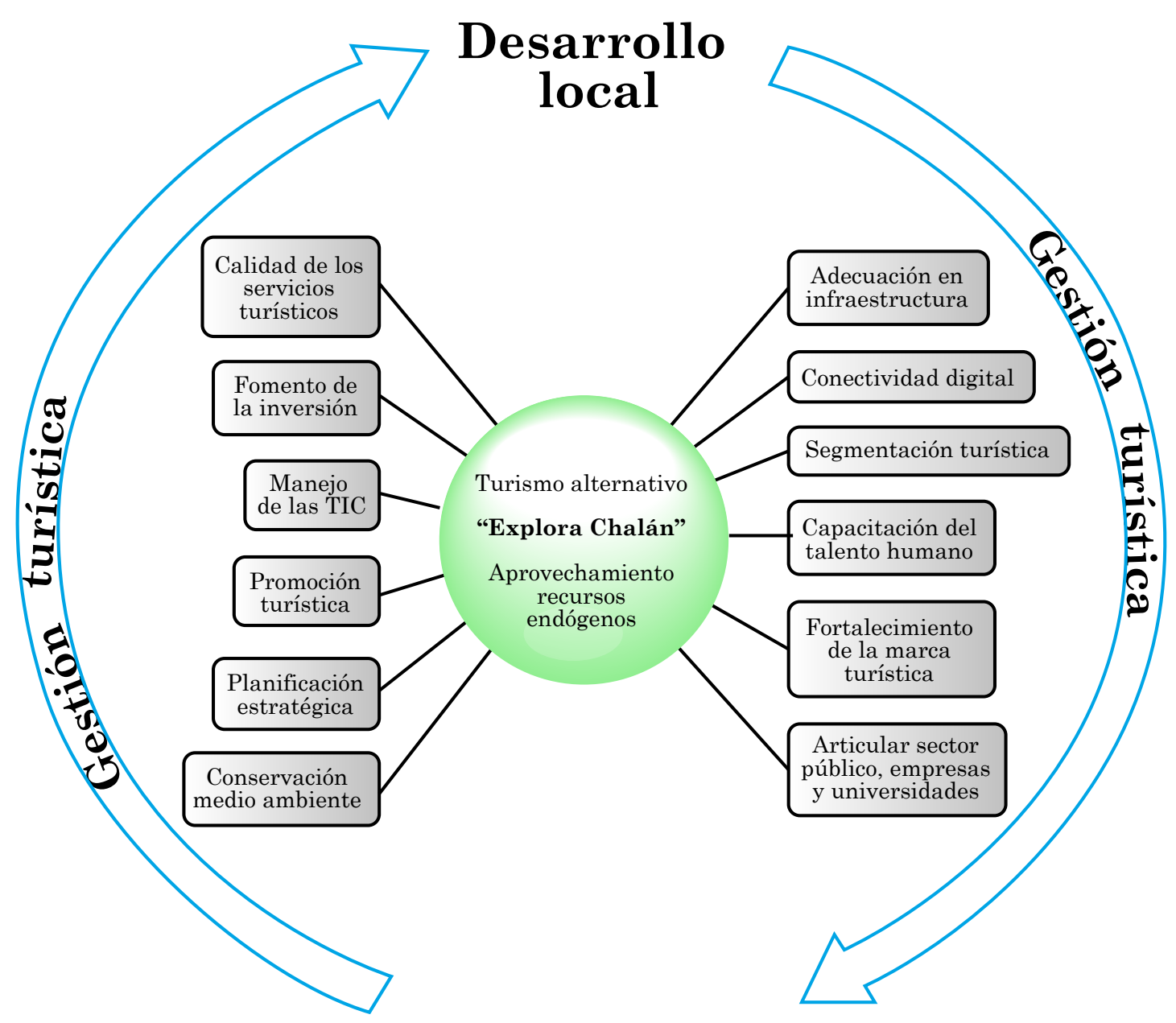

Fig. 7. Gestión turística para el desarrollo local

Fuente: elaboración propia a partir de lo expuesto por Arroyo, 2017.

\section{Conclusiones}

En Colombia, existen territorios que se encuentran atrasados totalmente, desarticulado en su interior y con desigualdades económicas y sociales, y aquellos que por años fueron víctimas del conflicto armado que vivió el país; como el caso del municipio de Chalán (Sucre). La ejecución del Estado de políticas tradicionales de desarrollo basadas en metodologías y procesos rígidos, no han arrojado efectos positivos y alentadores para el crecimiento de las economías locales.
En este sentido, se propone el resurgir de las economías locales a partir del uso sostenible de sus recursos endógenos como mecanismo de desarrollo local que involucre la participación activa de la comunidad y demás actores encargados de formular y ejecutar políticas y planes tendientes a estimular el desarrollo empresarial, económico, social y tecnológico generando sostenibilidad y autonomía en los territorios. Por ello, la construcción de planes estratégicos de desarrollo local se convierte en herramientas de desarrollo que pueden ser aplicados a un territorio determinado en busca de nuevas 
alternativas que conduzcan al fomento productivo, el desarrollo de infraestructuras, el desarrollo social y el capital humano.

Por lo anterior, se aplicó la metodología para la elaboración de estrategias de desarrollo local Silva (2003), en sus diferentes etapas (diagnóstico, vocación, definición de objetivos estratégicos y específicos, definición de la estrategia local y la elaboración del plan de inversión), en el municipio de Chalán en el departamento de Sucre, donde se evidenció el gran potencial de recursos endógenos con que cuenta representado en su posición geográfica, recursos naturales y culturales. Así mismo, a partir de los resultados obtenidos en la aplicación de la metodología, se propone como alternativa de desarrollo local el turismo alternativo, partiendo de un producto turístico denominado "EXPLORA CHALAN" donde su puesta en marcha permitirá la reactivación de un proceso de desarrollo en el territorio.

Además, se invita a un renacer de la comunidad rural mediante el desarrollo y fortalecimiento de sus capacidades en aras de alcanzar la diversificación económica rural que acabe con los paradigmas de desarrollo existentes. Finalmente, la planificación de estrategias de desarrollo local, reconoce las potencialidades de la comunidad local y la articulación que debe existir entre los actores públicos y privados, convirtiéndose en un proceso que permite superar las barreras que obstaculizan el mejoramiento de la calidad de vida y la generación de riquezas para la comunidad local.

\section{REFERENCIAS}

Acerenza, M. (2006). Conceptualización, Origen Y Evolución Del Turismo. México, D.F. Trillas.

Arroyo, L. (2017). Chalán munucipio destino turistico en el Departamento de Sucre: Diseño de un producto turistico 2017. [Tesis]. Universidad Tecnologica de Bolívar. Recuperado de http://biblioteca. utb.edu.co/notas/tesis/0070429.pdf
Becattini, G. (2002). Del distrito industrial marshalliano a la "teoría del distrito " contemporánea. Una breve reconstrucción crítica. Investigaciones Regionales, $1,9-32$.

Bringas, N. y Ojeda, L. (2000). El ecoturismo: ¿una nueva modalidad del turismo de masas? Economía Sociedad y Territorio, 2(7), 373-403. https://doi. org/10.22136/est002000436

Díaz, I. (2012). Turismo de aventura y participación de las mujeres en Jalcomulco. PASOS Revista de Turismo y Patrimonio Cultural, 10, 531-542. https://doi. org/10.25145/j.pasos.2012.10.068

Estados Unidos Mexicanos. Secretaría de Turismo (SECTUR). (2004). Turismo alternativo una nueva forma de hacer turismo. Serie Turismo Alternativo. México, D.F.: SECTUR. Recuperado de https://www.entornoturistico.com/wpcontent/uploads/2017/05/Turismo-Alternativo-una-nueva-forma-de-hacerturismo.pdf

FUA, G. (1988). The Balance between Industry and Agriculture in Economic Development. Londres: McMillan.

Ivanoba, A. y Ibañez, R. (2012). Tipologías y antecedentes de la actividad turística: turismo tradicional y turismo alternativo. En, Instituto Nacional de Ecología (Ed.), Medio ambiente y política turística en México, Tomo I (17-33). México, D.F.: Secretaria de Medio Ambiente y Universidad Autónoma de Baja California.

Osorio, M. (2010). Turismo masivo y alternativo. Distinciones de la sociedadmoderna/posmoderna. Convergencia, 17 (52), 235-260. Recuperado de http:// www.scielo.org.mx/pdf/conver/v17n52/ v17n52a10.pdf

Pérez, S. (2010). El valor estratégico del turismo rural como alternativa sostenible de desarrollo territorial rural. Agronomía Colombiana, 28(0120-9965), 507513. 
Rubert, J. y Fuertes, A. (2003). La economia regional en el marco de la nueva economía. Castelló de la Plana: Universitat Jaume.

Sanchis, J. (1999). Las estrategias de desarrollo local: aproximacion metodologica desde una perspectiva socio-economica e integral. Revista de Ingenieria de Organización, 21, 146160. Recuperado de http://www.revistadyo.com/index.php/dyo/article/ view/301

Silva, I. (2003). Metodología para la elaboración de estrategas de desarrollo local. Santiago de Chile: ILPES.

Solari, V. y Pérez, M. (2005). Desarrollo local y turismo: relaciones, desavenencias y enfoques. Economía y Sociedad, X, 49-64. Recuperado de http://www. redalyc.org/articulo.oa?id=51001603

Vázquez, A. (2009). Desarrollo Local, una estrategia para tiempos de crisis. Universitas Forum, 1, 1-11.

Vázquez, A. (2007). Desarrollo endógeno - Teorías y políticas de desarrollo territorial. Investigaciones Regionales, 11, 183-210.
Angélica María Aguirre Bertel es Ingeniero Industrial de la Corporación Universitaria del Caribe-CECAR de Sincelejo, (Colombia). Magíster en Administración, Universidad Tecnológica de Bolívar, Cartagena D.T, (Colombia). Coordinadora de Investigación Científica y AplicadaCECAR. Perteneciente al Grupo de investigación: Simulación de Tecnologías para procesos industriales (STI).

Lisset Paola Arroyo Oviedo estudio Administración de Empresa en la Corporación Unificada Nacional de Educación Superior-CUN, Sincelejo (Colombia). Es Magíster en Administración de la Universidad Tecnológica de Bolívar, Cartagena D.T, (Colombia). Docente de la Universidad de Sucre, Sincelejo (Colombia).

Clarisa Isabel Navarro Mesa estudio Administración de Empresa en la Universidad de Sucre, Sincelejo (Colombia). Es Magíster en Administración, Universidad Tecnológica de Bolívar, Cartagena D.T, (Colombia). Especialista en Gestión Pública, Escuela de Administración PúblicaESAP, Sincelejo (Colombia). Docente de la Universidad de Sucre, Sincelejo (Colombia). 